\section{Экологическое состояние лесных ландшафтов техногенной системы Красноярская ГЭС - г. Дивногорск}

\author{
Е. В. Авдеева ${ }^{1}$ \\ Сибирский государственный технологический \\ университет
}

\begin{abstract}
АННОТАЦИЯ
Для определения степени воздействия изменений внешней среды на рост деревьев был изучен радиальный прирост сосны обыкновенной в районе плотины Красноярской ГЭС и в г. Дивногорске. По методике Чайле и Ван Вика построены графики изменения величины логарифма радиального прироста во времени. Результаты обработки данных показали, что у деревьев, растущих в городе, проявляется выраженное в различной степени синхронное снижение прироста после 1958 г. (в период наиболее интенсивного строительства города), в той или иной мере восстановившегося к 1970 г. (к моменту завершения основного благоустройства города). Отрицательный угол наклона линейной модели деревьев в сообществе в районе нижнего бьефа Красноярской ГЭС свидетельствует о том, что изменившиеся микроклиматические условия после возведения плотины привели к замедлению прироста деревьев.
\end{abstract}

Ключевые слова: радиальный прирост, сосна обыкновенная, Красноярская гидроэлектростанщия, город-спутник.

\section{SUMMARY}

To define the degree of the environment changes influence on the tree growth the radial increment in common pine in the area of Krasnoyarsk HPS and Divnogorsk was investigated. Using Chaile and Van Vika techniques the diagrams of value change of the radial increment logarithm were constructed. Results of data processing have shown, that for the trees growing in the city, the synchronous decrease (reduction) of the increment expressed in a various degree after 1958 (in the period of the most intensive construction of the city), in this or that measure restored by 1970 (when the general development of the city had been finished) is shown. The negative angle of taper of linear model of trees in community in the area of the low reach of Krasnoyarsk HPS, testifies that changed microclimatic conditions after erection of the dam have resulted in delay of grows.

Keywords: a radial increment, a pine common, Krasnoyarsk hydroelectric power station, the city - satellite.

\footnotetext{
${ }^{1}$ Автор - доцент кафедры проектирования лесного оборудования, к.с/х.н.

(C) Е. В. Авдеева, 2003
}

\section{ВЗАИМОДЕЙСТВИЕ ГРАДОСТРОИТЕЛЬНЫХ И ПРИРОДНЫХ СИСТЕМ}

Большинство городов Сибири изначально были размещены на таежных территориях. Многие новые города проектируются и строятся в горной и равнинной тайге с включением лесных массивов в городскую застройку, что помогает смягчить суровые условия, улучшить микроклимат застройки, обогатить эстетическое качество городской среды. Определяющим фактором природных систем Сибири является низкая устойчивость ландшафтов к антропогенным нагрузкам (Крушлинский, 1986), которые при всей осторожности строителей и проживающих жителей возрастают, что приводит к изменениям условий роста деревьев. Эти изменения заключаются в вытаптывании травяного покрова, повреждении подроста и подлеска; разрушении лесной подстилки; нарушении водно-воздушного и температурного режимов почвы в результате ее уплотнения; увеличении запыленности, загазованности и загрязнения воздуха автотранспортом и промышленными выбросами $[1,3]$. Особенно наглядным показателем состояния дерева, его энергии роста и устойчивости является годичный прирост в толщину, который колеблется в определенных пределах в зависимости от изменения условий окружающей среды. Изучение радиального прироста деревьев сосны в условиях рекреационных нагрузок и промышленной среды показало, что в сосновых древостоях протекают два противоположных процесса: с одной стороны - деградация лесного массива с существенным снижением величины прироста деревьев и постепенным усыханием части из них [3]. С другой адаптация древостоя к изменившимся условиям произрастания с постепенным восстановлением текущего прироста в результате стабилизации стихийного вытаптывания почвы, в связи с созданием сети пешеходных дорожек и завершением основного строительства [1].

\section{АНАЛИЗ РОСТА ПРИРОДНЫХ ЛЕСОВ В СТРУКТУРЕ ГОРОДА}

Из городов-спутников г. Красноярска значительный интерес представляет опыт строительства молодого и наиболее крупного населенного пункта в пригородной зоне - г. Дивногорска. Своим рождением он обязан сооружению Красноярской ГЭС. Расположен в 40 км от г. Красноярска. Нижняя граница города начинается от р. Енисей, сам город поднимается по террасам-ступеням реки на высоту более 140 м. Его сложный рельеф (уклон до 15\%) определил широтное направление основных улиц и магистралей сквозного и обходного значения - все они параллельны р. Енисей и рельефу. Склон прорезан пятью логами, по трем из которых (Гермогенову, Филаретову и Безымянному) протекают ручьи. Главная композиционная ось города - Клубный бульвар. Меридиональный по направлению, он пересекает и связывает все террасы, все площади города: прибрежную, привокзальную, административно-культурного центра, автовокзальную и верхнюю.

В развитии Дивногорска заложена идея полного слияния города с природой [3]. Она окружает его, входит 
внутрь лесопарковыми массивами, составляет неотъемлемую часть жилых кварталов и микрорайонов его естественную среду. Во время строительства и эксплуатации городских объектов ведется постоянный санитарный уход за естественными лесными массивами, включенными в жилую застройку: проложена дорожно-тропиночная сеть из железобетонных плит, предотвращающая вытаптывание лесной подстилки, и ливневая канализация, отводящая воду с автодорог и оберегающая склоны от размывания, постоянно ведутся рубки ухода (в лесных массивах сухостой практически отсутствует).

$\mathrm{C}$ целью сохранения природной среды в городе проведены исследования по определению степени влияния антропогенного воздействия на рост, долговечность и состояние лесных массивов, включенных в городскую застройку. Работы проводились на шести участках: четыре из них расположены в селитебной зоне города (№ 2-5), первый - в районе плотины Красноярской ГЭС на левом берегу реки, шестой - в лесном массиве, вне зоны влияния города, в 5 км от его границы.
Слияние внутригородской застройки с ландшафтом составляет яркую особенность Дивногорска. Прибрежная терраса - широкая полоса бульвара со спусками к воде и причалом. Естественные зеленые массивы (участок 2) входят в систему микрорайонов и зоны отдыха этой террасы. Выше, в сохраняемой лесопарковой полосе следующей террасы (участок № 3), расположен комплекс административных зданий. Внутригородское озеленение представляет собой непрерывную систему, охватывающую всю территорию города (участок № 4), связанную с внешним ландшафтом. Опыт показывает, что это требование не всегда учитывалось на практике, особенно при застройке жилых территорий. Существующий к западу от селитебных территорий лесопарк, расположенный в верхней части города между Гермогеновым и Филаретовым ручьями, превращен в общегородской парк культуры и отдыха (участок № 5) и лыжный стадион, рассчитанный на использование жителями и гостями Дивногорска. Последняя терраса города граничит с лесным массивом, уходящим за водораздельный хребет (участок № 6). Состояние природных лесных массивов в городе и пригородных ландшафтов отражено в табл. 1 .

Таблица 1

Состояние природных массивов в Дивногорске и пригородном окружении

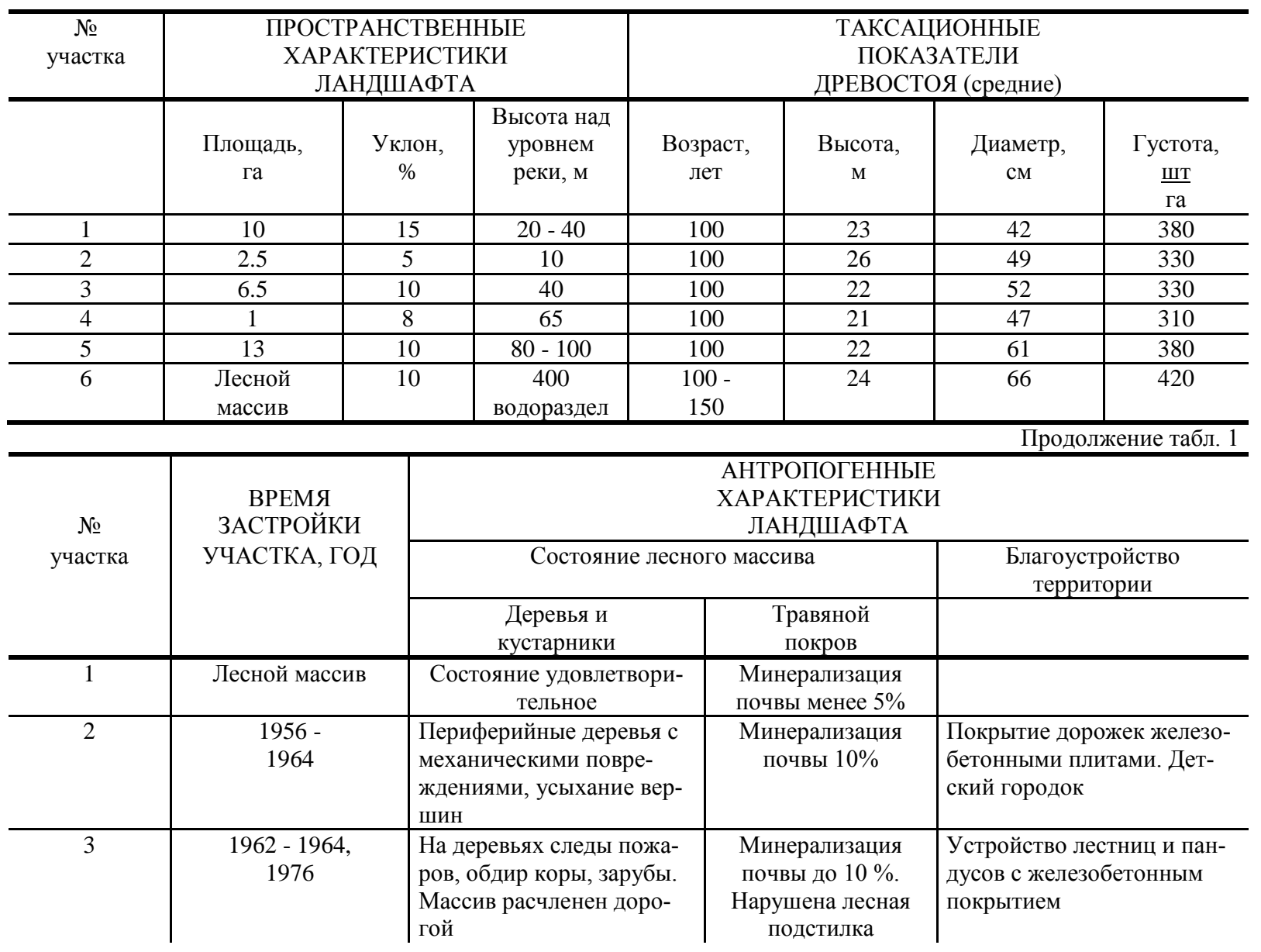




\begin{tabular}{|c|c|c|c|c|}
\hline 4 & $\begin{array}{c}1956- \\
1992\end{array}$ & $\begin{array}{l}\text { Деревья угнетены, повре- } \\
\text { ждены корни, усыхание } \\
\text { вершин, сухобочины, есть } \\
\text { сухостой }\end{array}$ & $\begin{array}{c}\text { Минерализация } \\
\text { почвы до } 40 \% \text {, мас- } \\
\text { сив пересечен го- } \\
\text { родскими сетями }\end{array}$ & $\begin{array}{l}\text { Пешеходные дорожки с } \\
\text { железобетонным покрыти- } \\
\text { ем, малые архитектурные } \\
\text { формы на детской площад- } \\
\text { ке }\end{array}$ \\
\hline 5 & $\begin{array}{c}1964, \\
1978-1992\end{array}$ & $\begin{array}{l}\text { Подлесок угнетен, засып- } \\
\text { ка корневых шеек }\end{array}$ & $\begin{array}{c}\text { Минерализация } \\
\text { почвы менее } 15 \%\end{array}$ & $\begin{array}{l}\text { Городской парк в стадии } \\
\text { строительства. Ручьи за- } \\
\text { хламлены } \\
\end{array}$ \\
\hline 6 & $\begin{array}{c}\text { Вне зоны } \\
\text { города }\end{array}$ & Хорошее & Нарушен слабо & \\
\hline \multicolumn{5}{|c|}{$\begin{array}{ll}\text { МЕТОДИКА } & \text { названа ими периодом свободного роста, второй } \\
\text { Осенью } 1991 \text { г. на каждом участке при помощи воз- } & \text { свойственно постоянство величины логарифма при- } \\
\text { растного бурава взято по 15 образцов древесины у } & \text { роста по площади сечения, и она может быть названа } \\
\text { лучших деревьев сосны, не имеющих механических } & \text { периодом роста в сообществе. В этот период может } \\
\text { повреждений, усыхания крон и превышающих по } & \text { наблюдаться снижение величины логарифма прир-- } \\
\text { размерам средние деревья. Ширина годичных слоев } & \text { ста по площади сечения в результате конкуренци, } \\
\text { определялась с помощью прибора "Измеритель ши- } & \text { возрастание его, стабилизация на другом уровне и } \\
\text { рины годичных колец" с точностью до 0.01 мм. По- } & \text { т.д. Поскольку были взяты приросты более крупных } \\
\text { лученные ряды прироста подвергнуты математиче- } & \text { деревьев, предполагалось, что влияние конкуренции } \\
\text { ской обработке с использованием пакета прикладных } & \text { на них минимальное, а снижение прироста можно } \\
\text { программ "Statgraphics". Обработка заключалась в } & \text { отнести на счет внешних воздействий. }\end{array}$} \\
\hline
\end{tabular}
устранении долговременной тенденции [4] или кривой большого роста при помощи показательностепенной функции вида

$$
Y=a \cdot X^{b} \cdot e^{c \cdot x} .
$$

Методом регрессионного анализа получены статистические характеристики уравнения.

\section{РЕЗУЛЬТАТЫ ИССЛЕДОВАНИЙ}

Анализ полученных данных показывает, что средняя величина прироста в начальный период у деревьев, растущих за городом, ниже, чем у деревьев, растущих на территории будущего города (соответственно 3 и 4.5 мм). К 60-летнему возрасту величина прироста в толщину у этих деревьев становится примерно равной (около 2 мм). В годы строительства г. Дивногорска прирост у деревьев на участке вне зоны влияния города составляет в среднем 1 мм и имеет тенденцию сохраняться на одном уровне. У деревьев, растущих в городе, в этот период наблюдается резкое снижение прироста до 0.4 мм, а затем постепенное его восстановление до уровня периода начала строительства. Среднее значение прироста оказывается заниженным вследствие того, что при устранении долговременной тенденции средняя линия оказалась под влиянием падения прироста в период интенсивного строительства города. Таким образом, у деревьев с долговременным снижением прироста данный метод оценки средней линии прироста не дает возможности отличить степень влияния внешних и внутренних факторов на его величину.

Для исключения влияния внешних условий на прирост по диаметру был использован метод, рекомендованный в работе Чайле и Ван Вика [5]. Они предложили строить графики зависимости логарифма прироста по площади сечения ствола на высоте груди от возраста. В этом случае график делится обычно на две части: первая характеризуется возрастанием величины логарифма прироста у молодых деревьев и

Анализ построенных графиков показывает, что деление на две части проявляется у всех деревьев. На контрольных участках у деревьев в период роста в сообществе наблюдаются незначительные колебания вокруг среднего уровня. На участках вне зоны города зависимость логарифма прироста деревьев от возраста может быть описана линейной функцией вида

$$
Y=a+b \cdot X
$$

Методом регрессионного анализа получены статистические оценки коэффициентов уравнений.

Анализ полученных данных свидетельствует о том, что на участке № 6 (контроль) в 14 случаях из 20, а на участке № 1 (нижний бьеф плотины) в 17 из 20 линейная модель является адекватной данному процессу с уровнем существенности более $95 \%$. По результатам исследований были построены гистограммы распределения коэффициента а. Их средние значения по участкам № 1 и 6 составляют соответственно 7.77 и 7.12. Кривая распределения соответствует нормальному закону.

Угол наклона графика характеризует величину изменения прироста (отрицательное значение свидетельствует о его замедлении). Абсолютное значение угла наклона линейной модели является весьма малой величиной (от 0.0003 до 0.01 ) на значительном отрезке времени, что еще раз подтверждает адекватность линейной модели периода роста деревьев в сообществе и правильность выбранного в данном случае метода математической обработки рядов прироста. Угол наклона графика имеет как положительное, так и отрицательное значение. Причем на контрольном участке нет ярко выраженного преимущества одного из значений: 6 деревьев имеют отрицательное значение, 8 - положительное. На участке, расположенном в районе плотины ГЭС, угол наклона линейной модели лишь в 4 случаях из 17 является положительным. Это говорит о том, что изменившиеся после возведения 
ГЭС микроклиматические условия привели к замедлению прироста деревьев.

У деревьев в городе выражено в различной степени синхронное снижение логарифма прироста после 1954 г., в той или иной мере восстановившегося к 1970 г. Это снижение оценивалось путем нормировки на средний уровень логарифма прироста каждого дерева за 1950-1954 гг. всех остальных величин логарифмов прироста. Полученные относительные величины (табл. 2) показывают, что на втором участке восстановили прирост только 8 деревьев из 15 , на пятом - 9, третьем - 10 и четвертом - 11 деревьев.

Таблица 2

Степень снижения прироста в толщину деревьев в городе

\begin{tabular}{|c|c|c|c|c|}
\hline \multirow[t]{2}{*}{ Показатели } & \multicolumn{4}{|c|}{ Номер участка } \\
\hline & 2 & 3 & 4 & 5 \\
\hline $\begin{array}{l}\text { Годы сниже- } \\
\text { ния величи- } \\
\text { ны годичного } \\
\text { прироста }\end{array}$ & $\begin{array}{l}1960 \text { - } \\
1969\end{array}$ & $\begin{array}{l}1959- \\
1967\end{array}$ & $\begin{array}{l}1958- \\
1973\end{array}$ & $\begin{array}{l}1957- \\
1970\end{array}$ \\
\hline $\begin{array}{l}\text { Годы } \\
\text { наибольшего } \\
\text { снижения } \\
\text { прироста }\end{array}$ & 1960 & 1960 & 1960 & $\begin{array}{c}1962 \\
1963\end{array}$ \\
\hline $\begin{array}{l}\text { Снижение } \\
\text { годичного } \\
\text { прироста от- } \\
\text { дельных де- } \\
\text { ревьев, \% }\end{array}$ & $3-17$ & $6-29$ & $4-21$ & $3-15$ \\
\hline $\begin{array}{l}\text { Площадь } \\
\text { снижения } \\
\text { прироста по } \\
\text { участкам, } \\
\text { усл. ед. } \\
\end{array}$ & 87.4 & 102.2 & 109.0 & 90.7 \\
\hline $\begin{array}{l}\text { Число дере- } \\
\text { вьев, восста- } \\
\text { новивших } \\
\text { прирост (из } \\
15), \text { шт. }\end{array}$ & 8 & 10 & 11 & 9 \\
\hline
\end{tabular}

Если учесть, что взят прирост лучших деревьев, без видимых признаков усыхания, то положение вызывает тревогу. Для сравнения деревьев и участков между собой рассчитан еще один показатель - условная площадь снижения прироста, или сумма отклонений логарифмов приростов после 1954 г. от среднего уровня предыдущих лет, принятого за единицу. По этому показателю наибольшие потери прироста наблюдаются на участке 4 , почти такие же - на участке $3(10-12 \%)$. Лучше прирост на остальных двух участках в городе.

Объяснить такие значительные потери прироста на участках 3 и 4 можно их малой площадью, но в этом вероятным фактором воздействия строительства на прирост деревьев следует считать запыленность воз- духа, особенно сильно проявляющуюся в летний период и связанную по времени со строительством дорог, что влекло за собой перемещение больших объемов грунта в пределах города. Известное воздействие могла оказать вибрация почвы, с чем можно связать усыхание деревьев вблизи дорог, поскольку загрязненный воздух распространяется на значительное расстояние от дорог.

В настоящее время наиболее вредным фактором является уплотнение почвы отдыхающими жителями, поэтому требуется проведение посадки кустарников под пологом сосны. Целесообразно также создание живых изгородей вдоль автодорог для ограничения распространения пыли и газов от автотранспорта.

\section{ВЫВОДЫ}

1. Во время интенсивного строительства города проявилось заметное снижение текущего прироста в толщину всех деревьев сосны в пределах городской черты. У большинства лучших деревьев сосны (63\%) произошло постепенное восстановление текущего прироста.

2. Требуется проведение дополнительных мероприятий по повышению жизнестойкости сосновых массивов, в частности: восстановление нарушенных ландшафтов; благоустройство берегов реки, ручьев; внедрение средозащитных пород озеленения с посадкой кустарников под пологом деревьев для регулирования движения отдыхающих, создание живых изгородей вдоль автодорог для ограничения распространения пыли и газов от автотранспорта.

Выполнение данных рекомендаций позволит улучшить градостроительный комфорт и, следовательно, решить задачу сохранения естественных лесных массивов в городе.

\section{СПИСОК ЛИТЕРАТУРЫ}

1. Иванов В. С. Влияние рекреационных нагрузок на радиальный прирост сосны // Лесное хозяйство. 1983. № 8. С. 14 - 16 .

2. Крушлинский В. И. Город и природа Сибири: Архитектурно-планировочные аспекты. Красноярск: Изд-во Красноярского ун-та, 1986. 232 с.

3. Таран И. В., Спиридонов В. Н. Устойчивость рекреационных лесов. Новосибирск: Наука, 1977. 197 c.

4. Черкашин В. П., Кузьмичев В. В. Статистический анализ рядов ширины годичных колец деревьев. Препринт ИЛиД СО АН СССР. Красноярск. 1977. 38 с.

5. Cilliers A. C., van Wyk J. H. A mathematical expression for the growth of trees in their dependence on time and density of stocking // Annals of the University of Stellenbosch. Capetown, 1938. V. 16, Sec. A. 36 p. 